\title{
Lingual Orthodontics Appliance, An Overview
}

\section{Rand Bin Salloum, Lama AlRassan, Nouf Almukhaizeem, Amira Albluwi, Reem Alfayez and Deema AlShammery*}

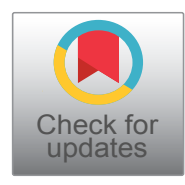

\author{
Riyadh Elm University, Riyadh, Saudi Arabia
}

*Corresponding author: Deema AlShammery, Assistant Professor, Riyadh Elm University, Riyadh, Saudi Arabia, E-mail: deema@riyadh.edu.sa

\begin{abstract}
As the numbers of adult patients who seeking orthodontic treatment are increasing rapidly, the demand of aesthetic orthodontics has been increased, many appliances have been introduced to the market. The ultimate of which are appliances bonded to the lingual surfaces of the teeth. The current mini review is provided on the historical development of lingual appliances, advantages as well as disadvantages and cases selection.
\end{abstract}

\section{Keywords}

Invisible braces, Lingual orthodontics, Lingual appliance

\section{Introduction}

Lingual orthodontics can correct most orthodontics problem that can be treated by conventional labial technique include malposition of teeth, anteroposterior discrepancies and pre-prosthetic surgical cases $[1,2]$. This system consists of specially designed brackets which is suitable to be placed in the lingual surface of the tooth [3]. The adult patients segment has higher resistance in committing to orthodontic treatments as opposed to younger patients [4]. With the increasing number of adult patients in orthodontic practices [5], the lingual orthodontic treatment has become a treatment of choice due to its aesthetic appeal for most adults [6].

\section{Development}

The first who develop the lingual orthodontic brackets was Kinja Fujita in 1967. In the 1975s Craven Kurz with Jim try plastic brackets to the lingual surface of the tooth because it was easy to reshape but they face many problems regard the patient comfort and bond- ing failures [7]. The Kurz lingual bracket developed and evolved from $1^{\text {st }}$ to $7^{\text {th }}$ generations (1976-1996) [8].

In 1970 the lingual orthodontics was initially common in Japan, and as aesthetic option in America [9]. The first patient was treated by using lingual appliance was in United States 1976 [2]. Over the years, problem-solving associated with lingual orthodontics was improved, and expanded around the world as well.

\section{Indications}

Many indications have been reported in the literature, aesthetic consideration is one of the most factor that play a major role of choosing this appliance over the conventional one. Clinician preference affect the choice in some cases as it has been reported that lingual orthodontics has many favorable outcomes like favorable position for anterior teeth [10], diastema closure [11], pre-prosthetic tooth movement, surgical cases [11,12], class I with generalized spacing or with mild crowding [12] and Class III cases [13].

\section{Advantage}

One of the good options for comprehensive treatment of most malocclusions is Lingual orthodontics [14] because of the lingual surfaces of the teeth appear to be less prone to caries than the buccal surfaces due to differences in surface morphology, plaque retention, salivary flow and the mechanical cleaning of surfaces by the tongue [15], and it is Best option for adolescent and adult patients [16] because of the esthetic concerns is very important factor to these patients [17] the main advantage of lingual orthodontics is the most aesthetic treatment [18]. 


\section{Disadvantage}

As there is a disadvantage in the conventional orthodontic treatment e.g. non-esthetic appearance there's also a disadvantage for placing brackets in the lingual surface especially the discomfort to the patient, speech problems, tongue irritation which can cause ulceration to the edge of the tongue [9].

On the other hand, the practitioner has also difficulties in the insertion and handling of these appliance [19] and the accuracy to brackets positioning due to anatomical variations in the lingual surface and long chair time for patients and orthodontists $[19,20]$.

Plus, there brackets overtime can cause change in tooth morphology [21].

\section{Conclusion}

Lingual orthodontics is a component of general orthodontics and as such it is subject to all the principles that govern correct patient selection and diagnosis. The future of lingual orthodontics is dependent on advances in technology related to appliance design and laboratory procedures. Lingual appliance treatment is suitable for most orthodontic patients and is the best choice for adult patients who reject the conventional visible appliances for social or professional reasons and demands esthetics.

\section{References}

1. Pauls A (2010) Therapeutic accuracy of individualized brackets in lingual orthodontics. J Orofac Orthop 71: 348361.

2. Echarri P (2004) Lingual orthodontics complete technique, step by step. AJODO 125: 649-650.

3. Gupta A, Ansari A, Krishna Nayak US, Agarwal A, Savana KA (2014) Lingual approach of orthodontic treatment: A case report. Int J Adv Health Sci 1: 33-36.

4. Jenner JD, McLean BD (1998) The lingual appliance. In: Fricker JP, Orthodontics and Dentofacial Orthopaedics. Tidbinbilla Pty Ltd, Canberra, 227-251.
5. Proffit WR (2000) Treatment for adults. In: Proffit WR, Contemporary orthodontics. ( $3^{\text {rd }}$ edn), Mosby, St Louis, 644.

6. Fritz U, Diedrich P, Wiechmann D (2002) Lingual technique-patient's characteristics, motivation and acceptance. J Orofac Orthop 63: 227-233.

7. Romano R (1998) Lingual orthodontics, BC Decker, Ontario.

8. Fiona Grist (2010) Basic guide to orthodontic dental nursing, John Wiley \& Sons, 155-165.

9. Fiona Grist RDN (2010) Fixed appliances-indirect bonding and lingual orthodontics. Blackwell Publishing Ltd.

10. Wiechmann D (1999) Lingual orthodontics (part 1): Laboratory procedure. J Orofac Orthop 60: 371-379.

11. Echarri $P$ (1988) Segmental lingual orthodontics in preprosthetic cases. J Clin Orthod 32: 716-719.

12. Prabakar R, Vikram NR, Saravanan R, Karthikeyan MK, Rajesh R, et al. (2012) Lingual orthodontics. IJMH 1: 16-18.

13. Gupta A, Kohli VS, Hazarey PV (2005) Lingual orthodontics-a review part 1. J Ind Orthod Soc 38: 46-54.

14. Bhandari D, Anbuselvan J, Karthi M (2014) History of lingual orthodontics-from past, present and future. JIDENT 2: 1-5.

15. van der Veen $\mathrm{MH}$, Attin R, Schwestka-Polly $\mathrm{R}$, Wiechmann D (2010) Caries outcomes after orthodontic treatment with fixed appliances: Do lingual brackets make a difference? Eur J Oral Sci 118: 298-303.

16. George RD, Hirani S (2013) Fully-customized lingual appliances: How lingual orthodontics became a vaible treatment option. J Orthod 40: S8-S13.

17. Pablo Echarri (2016) lingual orthodontics: Patient selection and diagnostic consideration. Seminars in Orthodontics 12: 160-166.

18. Gupta A, Thukral R (2015) Lingual orthodontics-an esthetic consideration. J Adv Med Dent Sci Res 3: S54-S56.

19. Papageorgiou SN, Konstantinidis I, Papadopoulou K, Jäger A, Bourauel C (2014) Clinical effects of pre-adjusted edgewise orthodontic brackets: A systematic review and meta-analysis. Eur J Orthod 36: 350-363.

20. Geron S (2008) Self-ligating brackets in lingual orthodontics. Seminar in Orthodontics 14: 64-72.

21. Fujita K (1982) Multilingual bracket and mushroom arch wire technique. Am J Orthod 82: 120-140. 